\title{
A condição docente do bibliotecário escolar na educação básica
}

\author{
The teaching condition of school librarian in basic education
}

Eduardo Valadares da Silva

Mestre em Educação pela Universidade Federal do Espírito Santo - UFES. Bibliotecário escolar na Prefeitura Municipal de Vitória - ES

E-mail: edu_valadares@yahoo.com.br

\begin{abstract}
Silvana Ventorim
Doutora em Educação pela Universidade Federal de Minas Gerais - UFMG.

Professora Adjunta do Departamento de Linguagens, Cultura e Educação e do Programa de Pós-Graduação em Educação do Centro de Educação da Universidade Federal do Espírito Santo - UFES.

E-mail: silventorim@ hotmail.com
\end{abstract}

\begin{abstract}
Resumo
Este artigo tematiza a função do bibliotecário escolar no contexto do debate sobre o trabalho e a condição docente por meio de uma pesquisa bibliográfica qualitativa. Tem como objetivo analisar como o bibliotecário escolar, compreendido como um trabalhador docente que atua na educação básica, desempenha diferentes atividades educativas com repercussão no processo de formação dos estudantes. A principal fundamentação teórica é fruto da pesquisa "Trabalho Docente na Educação Básica no Brasil", realizada pelo Grupo de Estudos sobre Política Educacional e Trabalho Docente da Universidade Federal de Minas Gerais. Constata-se, conclusivamente, que os bibliotecários escolares pouco participam das discussões relativas ao projeto político-pedagógico das escolas em que atuam, ainda que estas reconheçam sua importância no processo de desenvolvimento e formação dos estudantes por eles atendidos, o que demanda uma ressignificação da atuação desses profissionais no espaço escolar e das perspectivas teóricas que a norteiam.
\end{abstract}

Palavras-chave: Bibliotecário escolar. Trabalhador docente. Condição docente.

\begin{abstract}
This article discusses the role of school librarian in the context of the debate on the work and teaching condition through a bibliographical qualitative research. Aims to analyze how the school librarian, seen as a teaching worker engaged in basic education, plays different educational activities that have an impact on the training process of students. The main theoretical foundation is the result of the research "Teaching Work in Basic Education in Brazil", performed by the Group of Studies on Educational Policy and Teaching Work at the Federal University of Minas Gerais. It is conclusively noted that the school librarians do not participate very much in the discussions related to pedagogical political project of the schools where they act, although they recognize their importance in the development and training process of their students, which requires a reframing of these professionals at school and theoretical perspectives that guide.
\end{abstract}

Keywords: School Librarian. Teaching Worker. Teaching Condition.

Bibl. Esc. em R., Ribeirão Preto, v. 4, n. 2, p. 94-108, 2016. 


\section{Introdução}

No campo educacional, o trabalhador docente tem sido foco de intensas pesquisas com variadas temáticas associadas. No escopo do trabalho docente, tem-se observado que, a este trabalhador, se imputa a maior responsabilidade nos processos de aprendizagem, principalmente diante das constantes mudanças no contexto educacional. Cabe problematizar que essas modificações impulsionam um novo quadro no cotidiano escolar com alterações que interferem no contexto do trabalhador docente, geralmente causando o acúmulo de funções, a falta de qualidade nas condições de trabalho e a precariedade de políticas de formação, de remuneração e de reconhecimento profissional, entre outros.

O trabalho docente ganha, assim, contextos próprios de discussão, passando a constituir um temário específico de pesquisa, em especial, buscando observar como vem se constituindo a condição docente. As pesquisas da área indicam desafios na construção de políticas públicas que vislumbrem transformações em um quadro de precariedade que se estabeleceu ao longo dos anos. Nesse contexto, surge a necessidade de desenvolvimento de pesquisas e estudos que tenham como princípio uma ação política voltada para a investigação de uma dada situação, identificando o que é preciso mudar e como essas transformações podem ser desencadeadas a partir da experiência concreta e dos desafios presentes no cotidiano escolar, com todos os trabalhadores que dele fazem parte.

A partir dessas reflexões, destaca-se a pesquisa Trabalho Docente na Educação Básica do Brasil - TDEBB como um estudo que busca identificar como vem se constituindo o trabalho docente, partindo de diversas realidades brasileiras e das experiências concretas vivenciadas na escola.

Conforme explicitam Bartolozzi, Oliveira e Vieira (2012, p. 11) a pesquisa TDEBB

[...] analisa o trabalho docente nas suas dimensões constitutivas, identificando seus atores, o que fazem e em que condições se realiza o trabalho nas unidades de educação básica da rede pública e conveniada, tendo como finalidade subsidiar a elaboração de políticas públicas no Brasil, especificamente nos estados pesquisados.

A finalidade da pesquisa TDEBB é analisar a condição docente do profissional da educação, suas condições de trabalho, os elementos constitutivos da identidade docente, os processos de formação inicial e continuada, dentre outros aspectos, a partir da realidade dos estados do Pará, do Rio Grande do Norte, de Goiás, do Paraná, de Santa Catarina e do Espírito Santo nos anos de 2009 e 2010. O estudo foi coordenado nacionalmente pelo Grupo de Estudos 
sobre Política Educacional e Trabalho Docente da Universidade Federal de Minas Gerais Gestrado/UFMG e, no Espírito Santo, coordenado pelo Núcleo de Estudos em Políticas Educacionais da Universidade Federal do Espírito Santo - NEPE/UFES.

O universo da pesquisa compreendeu 664.985 sujeitos docentes e 34.556 unidades de ensino de Educação Básica das redes públicas e conveniadas dos sete estados investigados. Dentre eles, o Espírito Santo apresentou o menor quantitativo de estabelecimentos e o segundo menor quantitativo de professores, com dados coletados por meio do survey, aplicado em 78 escolas de educação infantil, ensino fundamental e ensino médio dos municípios de Vitória, Nova Venécia, Santa Tereza, Viana e Guarapari, nos quais entrevistou-se 1.481profissionais da educação básica. Diante da ampla proposta desta pesquisa, entendemos ser importante buscar possíveis desdobramentos e, assim, trazemos neste artigo, uma análise categorizada sobre os bibliotecários escolares que atuam nas unidades de ensino pesquisadas no estado do Espírito Santo e que responderam ao survey.

No universo de sujeitos participantes da pesquisa no Espírito Santo, foram identificados doze bibliotecários, dentre os quais, dez atuam no âmbito das instituições municipais, e desses dez, seis atuam na Rede Municipal de Ensino de Vitória conforme demonstrado na Tabela 1.

Tabela 1 - Bibliotecários que participaram da pesquisa TDEBB no Espírito Santo.

\begin{tabular}{|c|c|c|c|c|}
\hline \multirow{2}{*}{ Município } & \multicolumn{3}{|c|}{ Abrangência } & \multirow{2}{*}{ Total } \\
\cline { 2 - 4 } & Municipal & Estadual & Conveniada & \\
\hline Guarapari & 2 & 0 & 0 & 2 \\
\hline $\begin{array}{c}\text { Nova } \\
\text { Venécia }\end{array}$ & 0 & 1 & 0 & 1 \\
\hline Viana & 2 & 0 & 0 & 2 \\
\hline Vitória & 6 & 1 & 0 & 7 \\
\hline TOTAL & 10 & 2 & 0 & 12 \\
\hline
\end{tabular}

Fonte: Relatório Pesquisa Trabalho Docente no Espírito Santo.

A pesquisa TDEBB considerou a realização de estudo documental sobre a política educacional nas redes de ensino envolvidas, a revisão de literatura a partir da produção acadêmica na área sobre o tema trabalho docente, a realização de um panorama do trabalho docente na educação básica no Brasil com dados estatísticos disponíveis na base do Instituto Nacional de Estudos e Pesquisas Educacionais Anísio Teixeira - INEP e a realização de um 
Eduardo Valadares da Silva e Silvana Ventorim

survey $^{l}$ sobre o trabalho docente na educação básica no Brasil, em sete estados, por meio de uma amostra de seus municípios.

Nesse contexto indaga-se o motivo pelo qual a pesquisa TDEBB considerou o bibliotecário escolar nesse universo de investigação. Diante dessa possível interrogação, Campello (2010, p. 185) nos traz dois estudos que têm, como fonte de pesquisa, documentações da área da biblioteca escolar e, como foco de análise, a ação educativa da biblioteca escolar, por conseguinte, do bibliotecário escolar. Para a autora,

[...] essa é a oportunidade que se oferece ao bibliotecário para exercitar a prática educativa mais ampla, contribuindo para desenvolver nos alunos habilidades informacionais. Entretanto, a escassa influência do bibliotecário na aprendizagem reflete-se perceptivelmente na forma como a pesquisa escolar acontece, conforme revelado por estudos, que observaram nítida disfunção no processo.

Campello (2010) defende que a ação educativa do bibliotecário passa por diferentes níveis, como a ação organizadora da biblioteca, mantendo o ambiente organizado de forma a otimizar a localização e manuseio das fontes disponíveis; a função de palestrante, que adota a estratégia de apresentação dos recursos e das potencialidades da biblioteca; a função de instrutor, que esclarece como se dão os usos das mais variadas fontes de informação possíveis; a função de tutor, que mostra os passos a serem seguidos para a execução de uma pesquisa, por exemplo e; por último, a função de orientador, quando o bibliotecário assume a função de auxiliar o estudante no entendimento e na apropriação das informações, considerando suas singularidades. Ou seja, é nesse momento que se pode perceber, mais evidentemente, que o bibliotecário escolar se torna um sujeito ativo no processo de aprendizagem do estudante, um trabalhador que assume sua atividade como profissional da educação, participando do planejamento, da implementação e da avaliação do processo de ensino-aprendizagem na instituição educativa.

Assim considerado,

A prática dos bibliotecários de bibliotecas escolares no Brasil reflete a importância que eles conferem à colaboração com os professores. Esses bibliotecários reconhecem que, para exercer seu papel educativo de forma adequada, precisam trabalhar com o apoio da equipe pedagógica e dos professores. Utilizam palavras como apoio, parceria, envolvimento e sintonia para caracterizar essa relação. Os bibliotecários brasileiros, no entanto, percebem as dificuldades associadas a essa relação. Consideram que o professor recorre pouco à biblioteca para suas atividades didáticas, mostrando resistência e às vezes desinteresse em utilizá-la (CAMPELLO, 2009a, p. $58)$.

\footnotetext{
${ }^{1}$ Survey consiste na aplicação direta do questionário com questões abertas e fechadas ao sujeito docente pelo pesquisador, o que permite apresentar os objetivos da pesquisa e do questionário e tirar dúvidas que os entrevistados tenham em certas perguntas.
} 
Nesse contexto, traz-se a reflexão sobre o aspecto legal da atuação do bibliotecário no ambiente da biblioteca escolar, visto que, em 24 de maio de 2010, foi publicada a Lei Federal $\mathrm{n}^{\circ}$ 12.244, que trata sobre a universalização das bibliotecas nas escolas do Brasil. Essa lei determina a obrigatoriedade de as escolas contarem com um acervo de livros de, no mínimo, um título para cada aluno matriculado. Ainda que seja um passo inicial, haja vista o grande esforço para que a legislação seja cumprida na totalidade, é oportuno que se multipliquem e se estimulem estudos e pesquisas que documentem as realizações e o conhecimento disponível sobre a biblioteca na escola e sobre a atuação do bibliotecário no contexto escolar no Brasil.

Diante do exposto, objetivamos analisar como o bibliotecário escolar, compreendido como um trabalhador docente que atua na educação básica, desempenha diferentes atividades educativas com repercussão no processo de formação dos estudantes.

Para atingir esse objetivo, metodologicamente realizamos uma pesquisa do tipo bibliográfica, na qual são descritas as principais fundamentações apresentadas na pesquisa TDEBB, por meio dos seus resultados relacionados à atuação do bibliotecário escolar como um docente.

\section{O bibliotecário, um trabalhador docente?}

Revisitar essa pesquisa, nosso principal referencial para constituição de uma pesquisa bibliográfica qualitativa, tomando como foco de análise os 12 bibliotecários escolares que responderam ao survey, é inquietante, pois ainda se vive numa sociedade que, em geral, concebe o trabalho do bibliotecário escolar como uma atividade que exige exclusivamente competências técnicas, desprezando suas dimensões políticas, estéticas e éticas, inclusive nos casos em que ele atua no contexto escolar da educação básica, o que pressupõe um desempenho voltado, fundamentalmente, para a formação dos sujeitos que são contemplados pela sua performance.

A pesquisa TDEBB, por se tratar de um estudo que objetiva, dentre outras possibilidades, "investigar em que medida as mudanças trazidas por uma nova regulação educativa produzem efeitos sobre a organização escolar e sobre os docentes, sua identidade e trabalho" (BARTOLOZZI, OLIVEIRA e VIEIRA, 2012, p. 11), provoca um movimento em torno do repensar como esse bibliotecário se vê e como ele é visto pelo coletivo escolar e quais suas angústias e expectativas com relação à educação, analisando dimensões que passam pelos processos de formação inicial e continuada, pela participação nas discussões pedagógicas da 
escola, pelo reconhecimento profissional e pelas visões de futuro, no que diz respeito à atuação profissional.

Outro ponto importante que motiva tomar o estudo TDEBB como fonte de análise, é que ele considera os bibliotecários escolares como trabalhadores docentes, pois conforme Bartolozzi, Oliveira e Vieira (2012, p. 14), esses são "os profissionais que desenvolvem algum tipo de atividade de ensino ou docência, sendo compreendidos pelos professores e por outros sujeitos que exercem atividade de docência”. Ou seja, a função educativa não se restringe ao professor regente, mas a todos os sujeitos que implicam o processo de formação dos estudantes, sobretudo, quando se tem como referência a complexidade da instituição escolar.

Ainda assim, Dudziak (2001, p. 115) nos faz um contraponto, destacando que

Embora muitos bibliotecários se considerem educadores e possuam status para tal,
nem sempre as escolas e faculdades às quais estão vinculados percebem esses
profissionais como colegas engajados no processo educacional. Em geral, admite-se
que as coleções das bibliotecas são essenciais para a formação do estudante, mas a
necessidade de se educar para ter o domínio da informação fica muitas vezes em
segundo plano.

Um bibliotecário verdadeiramente educador necessita conhecer sua área de atuação específica, mas também necessita considerar a dimensão pedagógica da escola como seu lócus de atuação profissional, apropriando-se dos processos de ensino-aprendizagem segundo uma perspectiva transformadora de sujeitos críticos e em relação aos conteúdos e conhecimentos desenvolvidos na escola, pois “como agente educacional, o bibliotecário poderá iniciar os processos culturais de transformação da educação e da comunidade educacional e social. A biblioteca, enquanto instituição multicultural, pluralista e aprendente é a base desta transformação" (DUDZIAK, 2001, p. 131).

Ao longo dos anos, as formas de atuação dos professores na escola têm mudado, mas também o contexto da escola tem se ressignificado. Outras estruturas e espaços surgem ou se renovam e profissionais qualificados ocupam ou criam seus espaços de atuação, inclusive o bibliotecário escolar. Nesse contexto, a forma de os alunos aprenderem muda permanentemente, com o aparecimento de novos recursos e plataformas tecnológicas a cada momento, dentre outras mudanças imensuráveis. Assim, cabe também ao bibliotecário escolar de hoje um movimento de sensibilidade na potencialização da vida junto aos estudantes, sem perder de vista a necessidade de desenvolver saberes para a aprendizagem, ou seja, não basta prestar um serviço, mas é necessário desempenhar suas funções com vistas a se tornar um 
sujeito ativo, um trabalhador docente, nos processos de ensino-aprendizagem e no desenvolvimento de conhecimentos educativos sistematizados.

Vive-se num contexto sociocultural no qual se considera que

[...] educar em uma sociedade da informação significa muito mais que treinar as pessoas para o uso das tecnologias de informação e comunicação: trata-se de investir na criação de competências suficientemente amplas que lhes permitam ter uma atuação efetiva na produção de bens e serviços, tomar decisões fundamentadas no conhecimento [...] Trata-se também de formar os indivíduos para "aprender a aprender" (TAKAHASHI, 2000, p. 45).

Nesta sociedade produz-se uma avalanche de dados e informações que contribuem para a desestabilização das ordens e dos estilos sociais da modernidade, privilegiando a diversidade, a localidade e as especificidades que configuram uma nova sociedade, formada por sujeitos que podem trilhar seus próprios caminhos sem que, para isso, tenham a necessidade de adoção de metanarrativas. No contexto da escola, seus atores precisam ser interpretados e direcionados também para mediar, potencializar e tornar significativos os processos de aprendizagem e as reflexões de estudantes e professores.

Em um contexto sócio-histórico amplo, conforme nos aponta Santos (2009), somos sujeitos de uma sociedade em transição que vive um momento de diversas indefinições, frutos de promessas não cumpridas por uma sociedade pautada na hegemonia de poderes e conhecimentos. Na escola, que não está descolada dessa sociedade ampla que aqui se indica, consequentemente, também se passa por momentos de indefinições políticas, metodológicas e de identidade.

No que diz respeito ao bibliotecário escolar, nesse momento de tantas mudanças, esse profissional ainda vem buscando consolidação nesse lugar, principalmente no que tange a possíveis estratégias para se integrar ao currículo escolar, colaborando com professores no planejamento das atividades curriculares e no acompanhamento da aprendizagem dos estudantes, pois até pouco tempo, sua função, na visão de alunos, professores e gestores, limitava-se a atender solicitações de empréstimos de livros, a armazenar e cuidar dos acervos e a dar acesso a documentações sob sua guarda, ou seja, uma perspectiva de atuação de bibliotecário já ultrapassada e que deu lugar a um novo paradigma, no qual esse trabalhador contribui efetivamente como um dos protagonistas na aprendizagem dos estudantes, promovendo estratégias e atividades que aproximam a biblioteca do currículo, facilitando a aquisição e a formação global de conhecimentos. 
Nesse novo modelo educativo, a defesa pela necessidade de o bibliotecário inserir-se como um parceiro do professor, numa ação conjunta e colaborativa, com o objetivo de possibilitar o ensino e a aprendizagem com um olhar voltado para as questões do contexto escolar, é muito forte.

Campello et al (2013), quando realizaram um estudo do tipo estado da arte sobre as bibliotecas escolares, indicaram que as pesquisas publicadas têm apontado recorrentemente para a biblioteca escolar como fundamental para a aprendizagem na escola, o que demanda a necessidade de uma maior aproximação entre bibliotecário e professor nas atividades de formação, planejamento, avaliação, implementação de projetos e em parceria contínua e permanente, para que esse profissional possa exercer plenamente sua função educativa no espaço escolar e em quaisquer outros em que venha a transitar.

A partir desse cenário, que remete a uma ação colaborativa entre bibliotecário escolar e professor, é necessário que se passe a perceber o bibliotecário escolar como um trabalhador docente que desenvolve atividades essencialmente pedagógicas no contexto da escola.

Para Oliveira (2010), o trabalho docente é definido como a atividade realizada por sujeitos que atuam não restritamente na escola, mas também em outras instituições de ensino, nas diversas caracterizações institucionais, funcionais e de responsabilidades. Para a autora, essa atividade, extrapola a regência de classe, podendo ser considerados trabalhadores docentes professores, educadores, monitores, estagiários, diretores, coordenadores, supervisores, orientadores, atendentes, auxiliares, dentre outros.

O trabalho docente não se refere apenas à sala de aula ou ao processo de ensino formal, pois compreende a atenção e o cuidado, além de outras atividades inerentes à educação. De forma genérica, é possível definir o trabalho docente como todo ato de realização no processo educativo (OLIVEIRA, 2010, p. web).

Para Ferreira (2010) trabalho pedagógico é toda atividade cujo fim esteja relacionado à pedagogia, ou seja, que evidencie métodos, técnicas e avaliação intencionalmente planejados, vislumbrando a formação do conhecimento. Consequentemente, esse tipo de trabalho é "normalmente atribuído aos professores, [mas] o trabalho pedagógico pode ser realizado também por sujeitos que não são licenciados ou não estão na condição de professor".

Lievori (2012) define o trabalhador docente como todo agente que permeia o contexto escolar participando dos processos pedagógicos e destaca a atividade do sujeito docente, compreendida com base no trabalho real que é desenvolvido e seus processos subjetivos de produção concomitantes às situações vivenciadas. 
Dessa forma, o bibliotecário escolar, como trabalhador docente que desenvolve trabalhos pedagógicos no seu dia a dia, necessita ser escutado nas condições de trabalho que lhe são oferecidas e por ele são vivenciadas, numa busca pelo estabelecimento de relações e ações articuladas com os processos pedagógicos.

Diante dessas reflexões, pode-se visualizar possibilidades de inserção do bibliotecário escolar para além de atividades consideradas exclusivamente técnicas, mas também em situações que potencializem a disponibilização, o acesso e a apropriação da informação, bem como a produção de conhecimentos, e que favoreçam a troca de experiências entre trabalhadores docentes na constituição de um espaço colaborativo, no qual ações são discutidas em conjunto, num processo de tessitura de sentidos das experiências.

\section{A condição docente do bibliotecário escolar}

Apresentamos a seguir, uma síntese de reflexões teóricas dispostas em forma de subitens, inspirados nos levantamentos realizados pela pesquisa TDEBB, que dizem respeito ao desvio de função, ao vínculo profissional e ao plano de cargos e salários, bem como às formações inicial e continuada, à integração ao projeto político pedagógico e à importância do bibliotecário escolar na instrução e no desenvolvimento integral dos estudantes da educação básica e na aquisição, por eles, de competências elementares.

A partir desses subitens, que originalmente na pesquisa TDEBB se caracterizam como categorias de análise, pretendemos propor um guia inicial que auxilie em futuras pesquisas que almejem compreender o nível em que se dá a atuação do bibliotecário escolar como um trabalhador docente, considerando as peculiaridades locais.

\section{a) Desvio de função}

Uma questão importante a ser considerada na constituição do bibliotecário como um trabalhador docente se refere à diferença entre o cargo para o qual os trabalhadores docentes realizaram concurso público e a função que desempenham na escola.

A função de bibliotecário nas escolas de educação básica ainda é vista como uma função que não exige formação específica, o que contraria a legislação vigente, inclusive a Lei Federal 12.244 de 2010. Nesses casos, delegam-se a professores, muitas vezes afastados da sala de aula 
por problemas de saúde ou, em outros contextos, até mesmo funcionários com escolaridade, muitas vezes, no nível de ensino fundamental, a função de gerirem a biblioteca escolar.

No Brasil, esse quadro de sucateamento do ensino público tem se efetivado por meio de diferentes estratégias, que vão desde formas de organização do trabalho que penalizam os docentes, [...] quadro restrito de professores e demais trabalhadores de educação, desqualificação e desvalorização do trabalho dos docentes. (HECKERT et al., 2001, p. 129).

Defende-se aqui não a vulnerabilidade da profissão de bibliotecário ou de professor, mas a atuação desses profissionais de forma integrada e cooperativa, respeitando suas especificidades.

\section{b) Vínculo profissional e plano de cargos e salários}

Com a constatação da presença de professores desempenhando a função de bibliotecário, destacamos a necessidade de analisarmos algumas possibilidades para esse fenômeno.

A escassez de profissionais com formação específica para atuarem como bibliotecários, principalmente nas regiões distantes dos grandes centros, é a primeira hipótese que levantamos. Questões relacionadas à saúde desses professores que, ao serem diagnosticados como impossibilitados de atuarem em sala de aula, mas que ainda possuem condições de desempenhar outras funções que não demandem contato com alunos, são designados para atuarem na biblioteca da escola.

Para Gerlin (2006, p. 107)

[...] é fundamental compreender o que é função: atribuição ou o conjunto de atribuições que a administração confere a cada categoria funcional, ou cometida individualmente por servidores em atividades eventuais. Para ele, função distingue-se de cargo já que todo cargo tem função, mas pode haver função sem cargo. $\mathrm{O}$ autor evidencia que o magistério pode ter duas atribuições: docência e suporte pedagógico e, quando não é obedecida essa regra legal, é caracterizado desvio de função.

Essa segunda hipótese é a mais encontrada na realidade da maioria das redes de ensino do país, principalmente do setor público. 


\section{c) Formação inicial e continuada}

O pequeno ou nenhum reconhecimento nas políticas educacionais acerca da importância da atuação de profissionais bibliotecários qualificados nos espaços da biblioteca escolar, delegando a professores impedidos de atuarem em sala de aula por problemas de saúde e outros impeditivos ou a outros servidores sem formação específica, como funcionários de empresas terceirizadas ou de nível fundamental e médio, desestimulam o interesse pela busca de formação continuada dos bibliotecários.

Pode-se também refletir sobre a postura dos sistemas de ensino de ignorar a necessidade de um profissional na função de gerir a biblioteca da escola, o que pode levar à inferência de que tais sistemas, especialmente os participantes da pesquisa, desconsideram que todo o espaço escolar se caracteriza como espaço-tempo de ensino-aprendizagem. Isso pode ser confirmado não apenas nas concepções teóricas e nos discursos estabelecidos acerca da escola, mas, principalmente, em suas vivências cotidianas, na negação dos espaços-tempos da biblioteca escolar como também constituinte e lócus daqueles sujeitos praticantes que realizam o currículo na escola e que, por isso, também merecem especial atenção ao seu funcionamento no que diz respeito à sua estrutura física e de equipamentos, bem como à profissionalização de sua equipe de trabalho.

Com isso, é latente a necessidade do profissional bibliotecário buscar participação em formações continuadas na área da educação, visto que a maioria dos currículos de formação inicial dos cursos de biblioteconomia no Brasil não são contemplados com a oferta de disciplinas obrigatórias relacionadas à atuação na biblioteca escolar a partir de uma matriz de pensamento ligada às perspectivas educacionais, como constatado, por exemplo, no Espírito Santo, onde o único curso superior em Biblioteconomia é oferecido pela Universidade do Espírito Santo, somente no turno noturno, e sua grade curricular (UNIVERSIDADE..., 2010) não tem, explicitamente contemplada, nenhuma disciplina obrigatória ou optativa que aborde aspectos educacionais relacionados à Educação Básica.

As formações continuadas nas várias áreas da educação poderão se tornar importantes potencializadoras na formação de bibliotecários mais reflexivos e conscientes de sua responsabilidade de operarem ativamente na educação, implementando políticas públicas como trabalhadores transformadores do processo educativo na escola, o que torna essas formações imprescindíveis para suprir as naturais lacunas oriundas dos cursos de graduação em biblioteconomia e que 
[...] o repensar da formação continuada do bibliotecário torna-se um instrumento formador de novas concepções acerca-se da educação, da práxis, da visão holística de homem no mundo, e como aquela que tem dimensões coletivas na contribuição da emancipação e autonomia profissional. A formação continuada deve preparar bibliotecários reflexivos com responsabilidade para o desenvolvimento profissional e a participação na implementação de políticas educacionais e como agentes de transformação do processo educativo (PEREIRA, 2009, p. 4).

\section{d) Integração ao projeto político pedagógico}

O distanciamento do bibliotecário escolar das discussões que atravessam o cotidiano da escola é marcante e, no que diz respeito ao seu conhecimento e à sua inserção nos projetos político-pedagógicos das escolas, sua participação torna-se assaz importante, por esse documento configurar-se como o registro das questões que são pensadas para a escola e por ela, bem como por materializar a diversidade de diretrizes que são planejadas.

Em sua pesquisa, Campello (2009b, p. 99) evidencia que

A biblioteca é imprescindível porque ela se torna um grande aliado no desenvolvimento dos projetos pedagógicos, ocupando assim, lugar de destaque na instituição, fornecendo informação e criando perspectivas para a dinamização do saber na escola, de modo que a ação e interação aconteçam.

Compreende-se que, se não há o estabelecimento de um diálogo intenso também do bibliotecário escolar nessas questões, existe a possibilidade de que o olhar sobre a biblioteca se conforme a partir de uma perspectiva restrita para o que se espera da dinâmica de atuação dos bibliotecários, e não para uma dinâmica de parceria e de colaboração com todos os sujeitos da escola.

\section{e) Importância do bibliotecário escolar na instrução e no desenvolvimento integral dos estudantes da educação básica e na aquisição, por eles, de competências elementares}

A convicção acerca da atuação do bibliotecário como um trabalhador docente envolvido em todos os processos de produção de conhecimentos que são estabelecidos no cotidiano escolar, não só na sala de aula, mas em outros ambientes de aprendizagem é senso comum em praticamente todas instâncias. Contudo, cabe um questionamento: será que esses profissionais tomam também para a si a responsabilidade de instrução dos alunos no processo de ensinoaprendizagem?

Perceber a integralidade presente no aluno requer reflexões sobre as concepções que engessam o contexto escolar. Olhar para o aluno como um sujeito integral, permeado de sentimentos, histórias e atitudes possibilita uma prática diferenciada nas relações produzidas no 
cotidiano escolar. Fazer parte e perceber a importância de sua inserção neste processo de constituição do sujeito como ser integral nos faz ratificar o pensamento de que os bibliotecários se veem como trabalhadores docentes, atuantes no movimento de aprendizagem.

Para Campello (2009b, p. 26) o bibliotecário escolar,

[...] embora tendo consciência de seu papel pedagógico, não deu ainda o salto para uma ação educativa mais ampla, representada pelo envolvimento em atividades de letramento informacional. Entretanto, consideramos que a situação acima descrita pode estar em processo de modificação.

O que se espera, é que esses profissionais tomem para si também sua parcela de responsabilidade para concretização desse desenvolvimento integral do alunado também a partir da biblioteca escolar.

\section{Considerações finais}

Temos convicção, a partir das perspectivas aqui apresentadas e defendidas, que o bibliotecário escolar pode se constituir como um trabalhador docente, desempenhando diferentes atividades educativas que repercutam diretamente no processo de formação dos estudantes, ainda que existam questões que necessitam ser refletidas com mais profundidade.

O não envolvimento de bibliotecários na discussão de projetos pedagógicos merece estudos mais aprofundados, pois leva a crer que haja um possível afastamento desse profissional dos diálogos pedagógicos no cotidiano escolar, o que pode prejudicar suas ações colaborativas na escola, mesmo que se reconheça sua importância no desenvolvimento e na instrução dos estudantes e que se perceba que ações conjuntas no cotidiano escolar são possíveis dentro de um contexto colaborativo, de troca de saberes, experiências e complementaridade.

Observa-se ainda, que o processo de ensino-aprendizagem na escola não se restringe ao professor regente, mas abarca uma diversidade de profissionais que atuam nesse lócus e influenciam de diversas maneiras o desenvolvimento dos estudantes. Destaca-se aqui a importância do bibliotecário escolar que, por vezes, ainda é visto, pelo senso comum, como um trabalhador que tem sua atuação voltada exclusivamente para o viés técnico da profissão e não como um mediador pedagógico.

Com base em pesquisas recentes, e no próprio fazer de vários desses profissionais, percebe-se que essas concepções vêm se transformando e potencializando o reconhecimento de 
uma profissão que tem como principal objetivo o processo de ensino-aprendizagem, mas que para tanto, exige uma profunda ressignificação da atuação desses profissionais e das perspectivas teóricas que a norteiam, no que diz respeito tanto à sua formação quanto ao seu desempenho profissional.

\section{Referências}

BARTOLOZZI, E.; OLIVEIRA, D. A.; VIEIRA, L. F. (Org.). O trabalho docente na educação básica: o Espírito Santo em questão. Belo Horizonte: Fino Traço, 2012.

CAMPELLO, B. S. Letramento informacional: função educativa do bibliotecário na escola. Belo Horizonte: Autêntica, 2009a.

Letramento informacional no Brasil: práticas educativas de bibliotecários em escolas de Ensino Básico.2009. 208 f. Tese (Doutorado em Ciência da Informação) - Escola de Ciência da Informação, Universidade Federal de Minas Gerais, Minas Gerais, 2009b.

Perspectivas de letramento informacional no Brasil: práticas educativas de bibliotecários em escolas de ensino básico. Encontros Bibli: revista eletrônica de biblioteconomia e ciência da informação, Florianópolis, v. 15, n. 29, p.184-208, 2010.

et al. Pesquisas sobre biblioteca escolar no Brasil: o estado da arte. Encontros Bibli: revista eletrônica de biblioteconomia e ciência da informação, Florianópolis, v. 18, n. 37, p. 123, 18 ago. 2013. Disponível em:

<https://periodicos.ufsc.br/index.php/eb/article/view/1518-2924.2013v18n37p123>. Acesso em: 16 ago. 2015.

DUDZIAK, E. A Information Literacy e o papel educacional das bibliotecas. 2011. 177 f. Dissertação (Mestrado em Ciências da Comunicação) - Escola de Comunicação e Artes da Universidade de São Paulo, São Paulo, 2001.

FERREIRA, L. S. Trabalho pedagógico. In: GRUPO DE ESTUDOS SOBRE POLÍTICA EDUCACIONAL E TRABALHO DOCENTE. Trabalho, profissão e condição docente. Belo Horizonte, [s.n.], 2010. Disponível em: < http://www.gestrado.org/?pg=dicionarioverbetes\&id=429> Acesso em: 9 dez. 2014

GERLIN, M. N. M. Fiando textos e contextos: a narrativa tece o trabalho de professores em bibliotecas escolares. Vitória, UFES: Dissertação (Mestrado em Educação) Programa de PósGraduação em Educação, 2006.

HECKERT, A. L. et al. A dimensão coletiva da saúde: uma análise das articulações entre gestão administrativa-saúde dos docentes, a experiência de Vitória. In: ATHAYDE, M. et al. (Orgs.). Trabalhar na escola? Só inventando o prazer. Rio de Janeiro: IPUB, 2001.

LIEVORI, S. E. O trabalhador docente na rede estadual do Espírito Santo: apontamentos sobre a carreira docente e suas condições de trabalho. In. BARTOLOZZI, E.; OLIVEIRA, D. 
A.; VIEIRA, L.F. (Org.). O trabalho docente na educação básica: o Espírito Santo em questão. Belo Horizonte: Fino Traço, 2012.

OLIVEIRA D. A. Trabalho docente. In: GRUPO DE ESTUDOS SOBRE POLÍTICA EDUCACIONAL E TRABALHO DOCENTE. Trabalho, profissão e condição docente. Belo Horizonte, [s.n.], 2010. Disponível em: <http://www.gestrado.org/?pg=dicionarioverbetes\&id=429> Acesso em: 09 set. 2015.

PEREIRA, G. A formação do bibliotecário escolar. In: CONGRESSO DE LEITURA NO BRASIL, 17, 2009. Campinas. Caderno de atividades e resumos. Campinas: UNICAMP, 2009. Disponível em: <http://alb.com.br/arquivo-morto/edicoes_anteriores/ anais17/txtcompletos/ sem01/COLE_1572.pdf>. Acesso em: 18 ago. 2015.

SANTOS, B. de S. A crítica da razão indolente: contra o desperdício da experiência. 8. ed. São Paulo: Cortez, 2009.

TAKAHASHI, T. (Org.) Sociedade da informação no Brasil. Brasília: Ministério da Ciência e Tecnologia, 2000. Disponível em: <http://livroaberto.ibict.br/bitstream/1 /434/1/ Livro\%20Verde.pdf $>$ Acesso em: 17 ago. 2015.

UNIVERSIDADE FEDERAL DO ESPÍRITO SANTO. Departamento de biblioteconomia. Vitória, 2010. Grade curricular versão 2007/2. Disponível em: <http://www.biblioteconomia.ufes.br/grade-curricular-versão-20072>. Acesso em: 10 set. 2015. 